\title{
Pigmented Villonodular Synovitis of the Ankle with Extensive Bone Involvement: A Case Report
}

\author{
by Remco J.A. van Wensen, $\mathrm{MD}^{1} \llbracket$, Michel P.J. van den Bekerom, $\mathbf{M D}^{2}$, Thomas W. Patt, MD $^{3}$, \\ Herman M. Peters, $\mathrm{MD}^{4}$, Eric Breemans, $\mathrm{MD}^{5} \square$
}

The Foot \& Ankle Journal 1 (1): 1

We describe a case of a 49 year old man who presented with swelling of his left ankle for two months. After standard X-ray, ultrasound investigation, MRI and histological examination, the patient was diagnosed with pigmented villonodular synovitis and bone involvement of the ankle. A complete resection of the tumour was performed. A large bone defect after the resection was filled with cancellous bone graft. In pigmented villonodular synovitis, symptoms are often remarkably discrete for long periods. The course of the disease is slow, but progressive and destructive. This warrants awareness of this entity, early diagnosis, and aggressive management.

Key words: Pigmented villonodular synovitis, ankle, bone involvement, benign tumour, diffuse giant cell tumor.

Abbreviations: LNS: Localised Nodular Synovitis, GCT: Giant Cell Tumor, PVS: Pigmented Villonodular Synovitis, MRI: Magnetic Resonance Imaging, CT: Computer Tomography, AP: AnteroPosterior, ROM: Range of Motion

Published online: January 1, 2008

The first description of localized nodular synovitis (LNS), a localised tenosynovial giant cell tumor (GCT), was by Chassaignac in $1852 .{ }^{1} \mathrm{He}$ described lesions of this nodular form arising in relation to the flexor tendon sheath of the middle and index finger.

\footnotetext{
Address correspondence to: Eric Breemans, Gelre Hospitals, location Lukas, Department of Orthopaedic Surgery, P.O. Box 9014, 7300 DS, Apeldorn, the Netherlands. Tel:+ 31555818181.

E-mail: Breemans@breemans.com

${ }^{1}$ Registrar Orthopaedic Surgery, Sint Maartenskliniek, Woerden, the Netherlands.

${ }^{2}$ Registrar Orthopaedic Surgery, Academic Medical Center, Amsterdam, the Netherlands.

3 Orthopaedic Surgeon, Sint Maartenskliniek, Woerden, the Netherlands.

${ }^{4}$ Pathologist, Gelre Hospitals, Apeldoorn, the Netherlands.

${ }^{5}$ Orthopaedic Surgeon, Gelre Hospitals, Apeldoorn, the Netherlands.
}

The term "pigmented villonodular synovitis" (PVS) was introduced by Jaffe, et al, in 1941 to denote a benign affection of the synovial membrane of joints, tendon sheaths, or bursae. ${ }^{2}$ In 1976 the GCT's were further subdivided in a diffuse and localised form by Granowitz and Mankin. ${ }^{3}$

PVS is a diffuse GCT and has a reported incidence of 1.8 patients per million. ${ }^{19}$ PVS develops most frequently in young adults, both men and women, but can start at any age.

It presents most commonly as a monoarticular arthritis in the knee, hip or hand, but it can also occur in smaller joints, including the ankle. ${ }^{2}$ PVS may be locally destructive and does not metastasize. ${ }^{8}$ The insidious progression of the disease and its local extent often lead to bone lesions that require surgical intervention. ${ }^{10-12}$ 


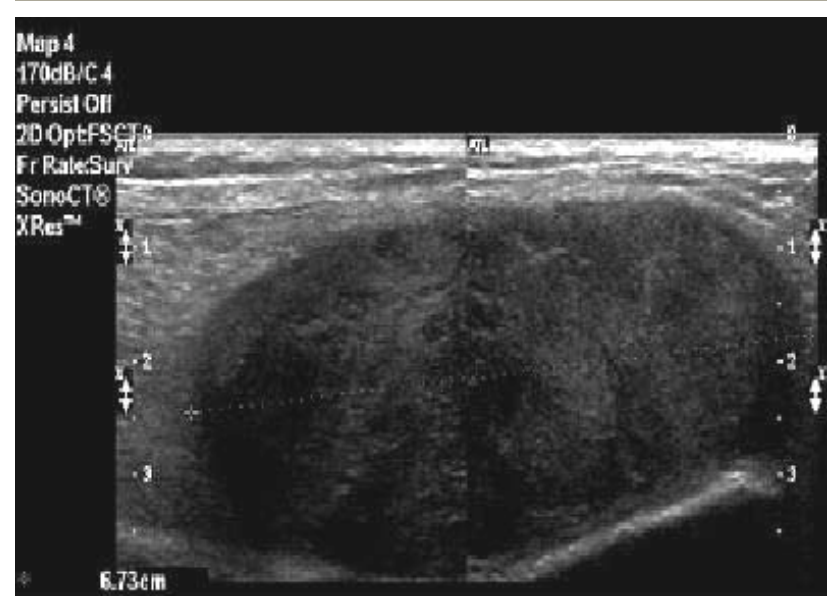

Figure 1 Preoperative ultrasound reveals a homogenous mass measuring $7 \times 3 \mathrm{~cm}$ in diameter. The tumor is well defined.

The MRI appearance is pathognomonic due to the iron deposition in the tumour, which has a magnetic moment. ${ }^{13-16}$ Histologically, the lesion is characterized by the presence of fibrous stroma, hemosiderin deposits and histiocytic infiltrates (foam cells or giant cells) in the synovial membrane. It may have many synovial protrusions that affect joints, bursae, and tendon sheaths. It has a typical yellow-brown appearance due to excessive deposits of hemosiderin and lipids. One characteristic finding of PVS is the ability of the hyperplastic synovium to invade the subchondral bone, producing cysts and erosions. 2-4 PVS can present as a localized or diffuse lesion. ${ }^{4}$ A nodular, villonodular and villous variety of the disease can be distinguished. The various types are histologically identical and probably constitute different manifestations of the same process. 2,6 The tumour, although benign, can cause joint and bone destruction.

Symptoms are often remarkably discrete for long periods and the course of the disease is slow and progressive. This warrants awareness of this entity, early diagnosis, and aggressive management. The usual treatment of PVS is complete excision of the tumour. The case we describe is rare because of its extensive bone involvement.

(C) The Foot \& Ankle Journal, 2008

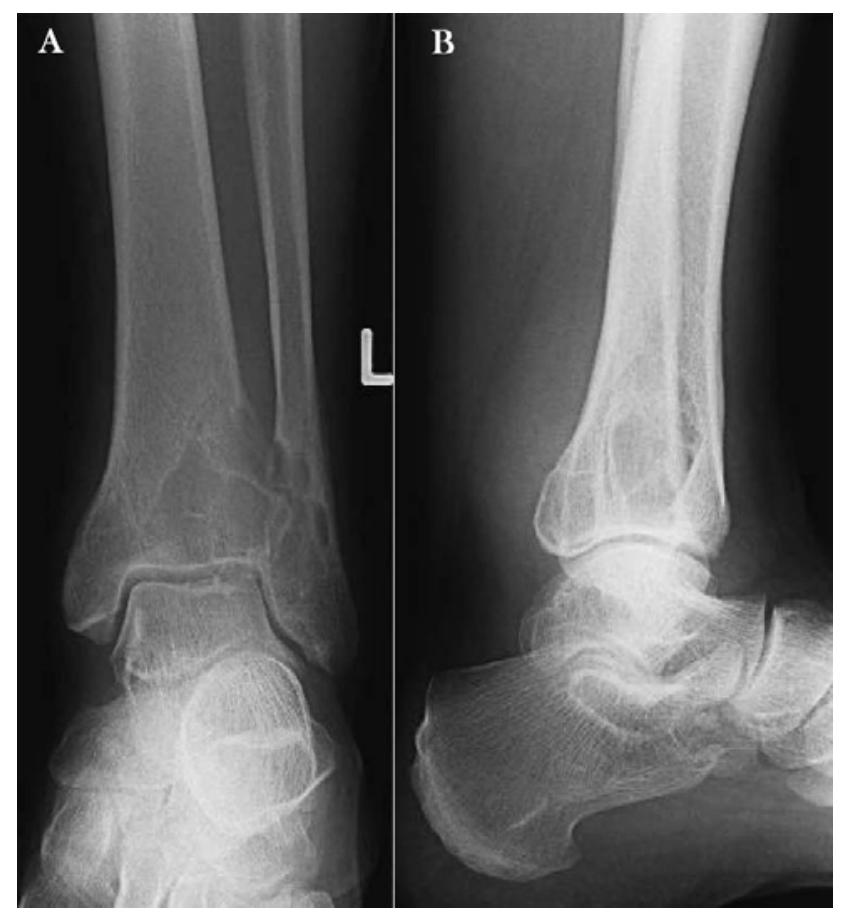

Figure 2AB Preoperative radiographs reveals an expanding, osteolytic tumor extending from the tibia to the fibula. No intra-articular involvement is appreciated.

\section{Case Report}

In March 2004 a 49 year old Italian man with complaints of swelling of his left ankle for the previous two months. He saw his general practitioner who requested an X-ray and ultrasound investigation. The ultrasound investigation revealed a well defined soft tissuetumour which expanded from the postero-lateral tibia and fibula in the direction of the membrana interossea. It appeared as a homogeneous solid mass measuring 7 x $3 \mathrm{~cm}$. (Fig. 1) X-ray investigation of the left ankle showed obvious bone abnormalities. An expanding osteolytic tumor in the lateral part of the tibia was observed. The soft tissues postero-lateral of the ankle was substantially enlarged. No calcifications were observed. The joint space was unaffected. (Fig. $2 \mathrm{AB})$ The radiologist referred the patient to the orthopaedic department. 


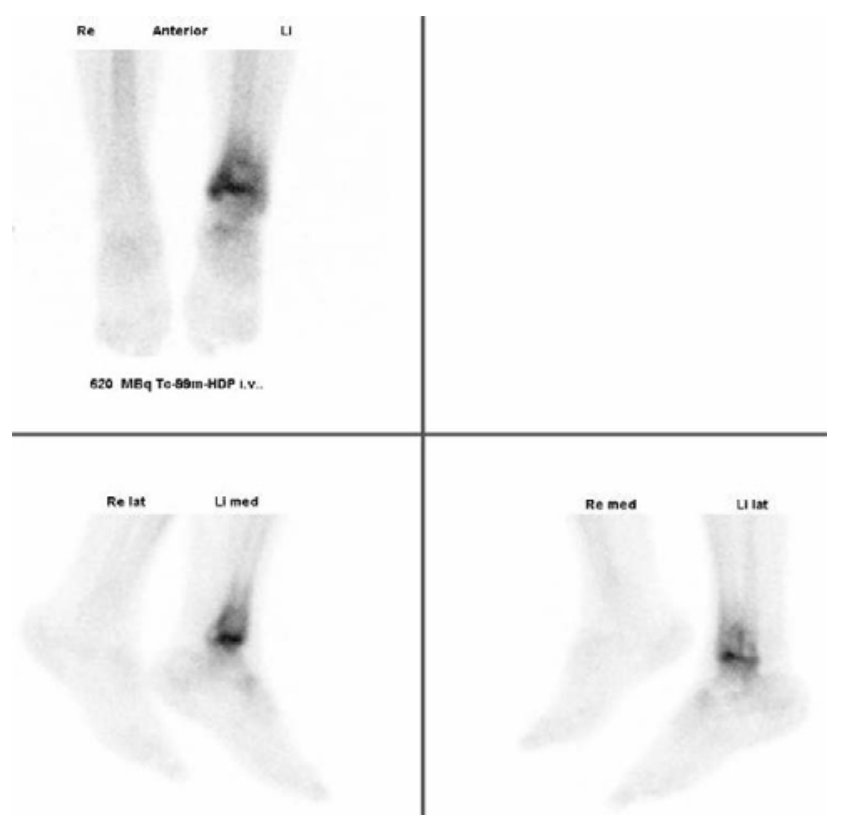

Figure 3 Bone scintigraphy reveals increased activity to the distal tibia and fibula.

In April 2004, this man, $90 \mathrm{~kg}$, length of $1.78 \mathrm{mtr}$, visited our outpatient orthopaedic clinic. He had an unremarkable medical history taking no medications and working part-time as a cleaner. He was complaining of pain and noticed a gradual increase in swelling above his left ankle after a long car drive. Several weeks later this swelling appeared while walking a short distance. On physical examination there was a noticeable swelling to the supra- and retromalleolar region of the left lateral malleolus. The overlying skin and soft tissue was healthy. There was local tenderness retromalleolar at the medial and lateral ankle joint. The ankle was stable and had full range of motion. There were no neurovascular abnormalities to the left ankle and foot.

The bone scintigraphy revealed an increased activity at the distal end of the left tibia and fibula. (Fig. 3) MRI scan: Transversal assimilations in FSE T2, SE T1 and SE T1 with contrast soluble and T2 sagital assimilation with fat saturation provided a solution to our diagnostical problem.

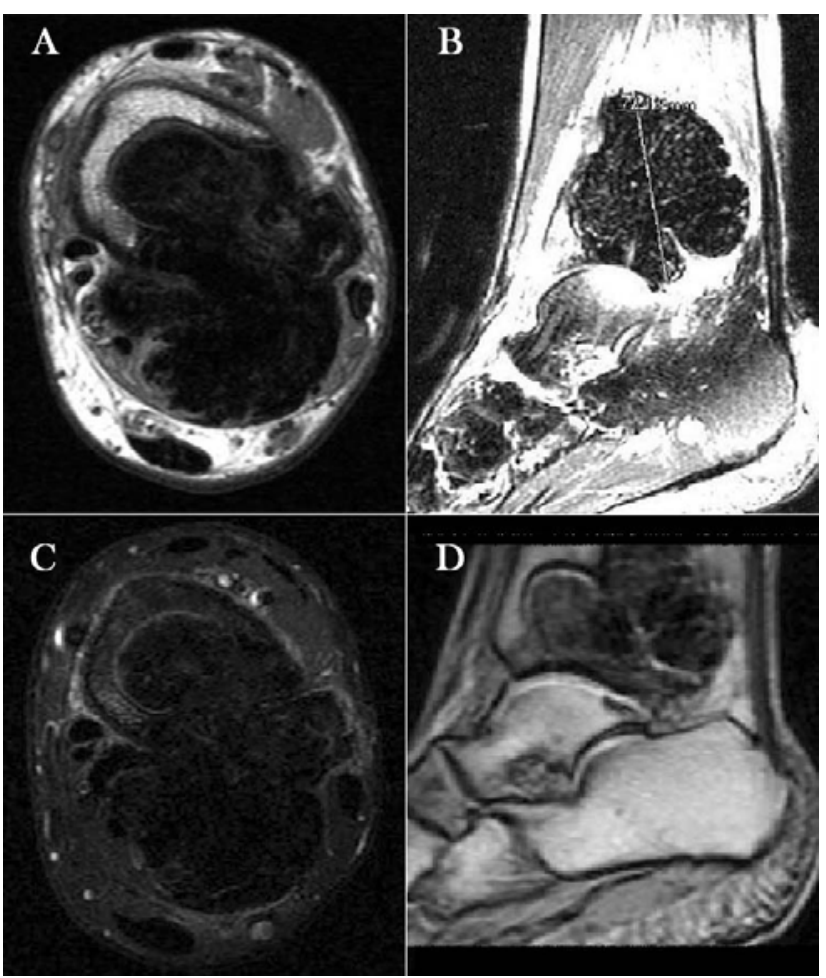

Figure $4 A B C D$ MRI scans with transversal assimilations in SE T1 (A) and SE T1 with contrast (C). Sagital assimilation in FSE T2 with fat contrast (B) and a sagital image of the 3 plane localizer (D).

MRI revealed a solid mass with regular lobulated surroundings expanding between the fibula and the tibia with bone involvement. The maximal diameter of the lesion was $7 \mathrm{~cm}$ and it expanded as far as the concavity of the distal tibial plateau. The signal intensity was homogeneous low with some areas of increased intensity in all sequences. This is considered a fairly typical presentation of PVS. (Fig. 4ABCD)

The patient underwent surgery six weeks later. Through a posteromedial incision of the distal one-third of the left tibia the brown tumour was removed. We observed joint damage caused by the tumour expanding to the lateral side of the tibia as well as the medial side of the fibula. The tissue was sent for histological examination. The defect was filled with allogenous bone grafts. The wound was closed after extensive brushing and packing with Spongostan $®$. 


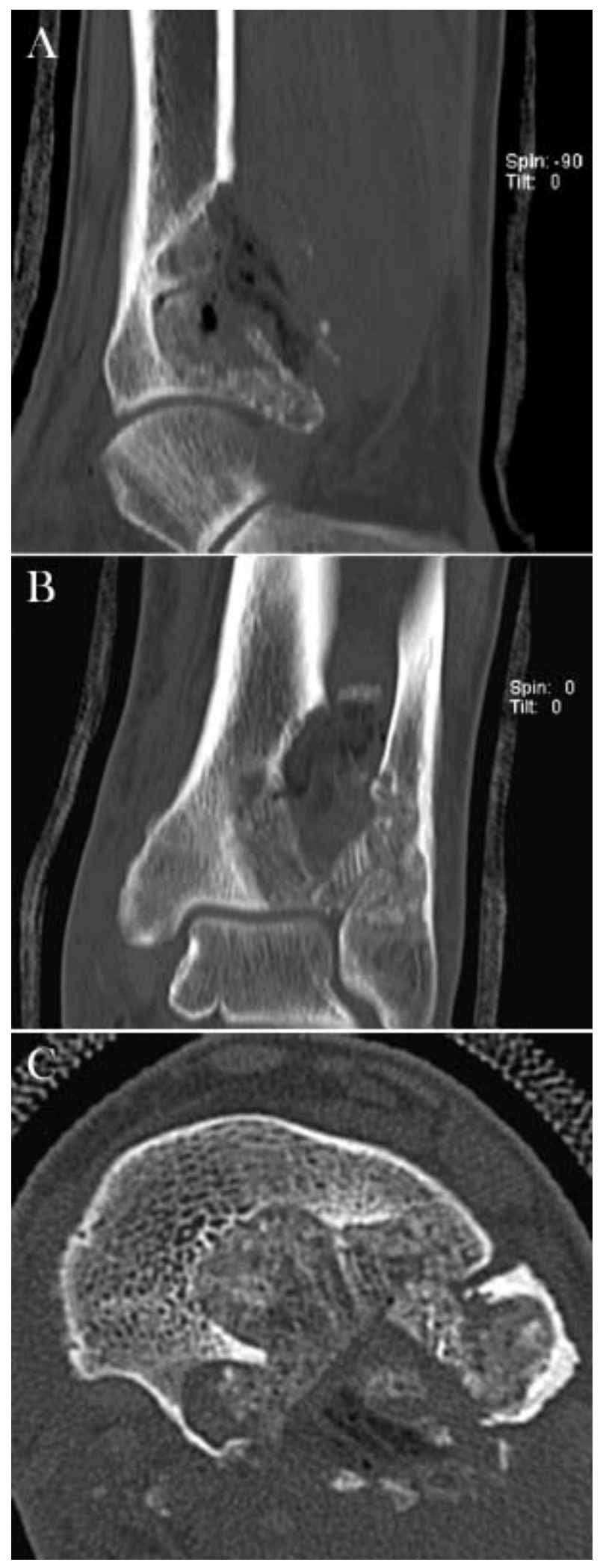

Figure 5ABC Post operative CT Scan showing some air pockets in the transplanted bone and soft tissues. (ABC)

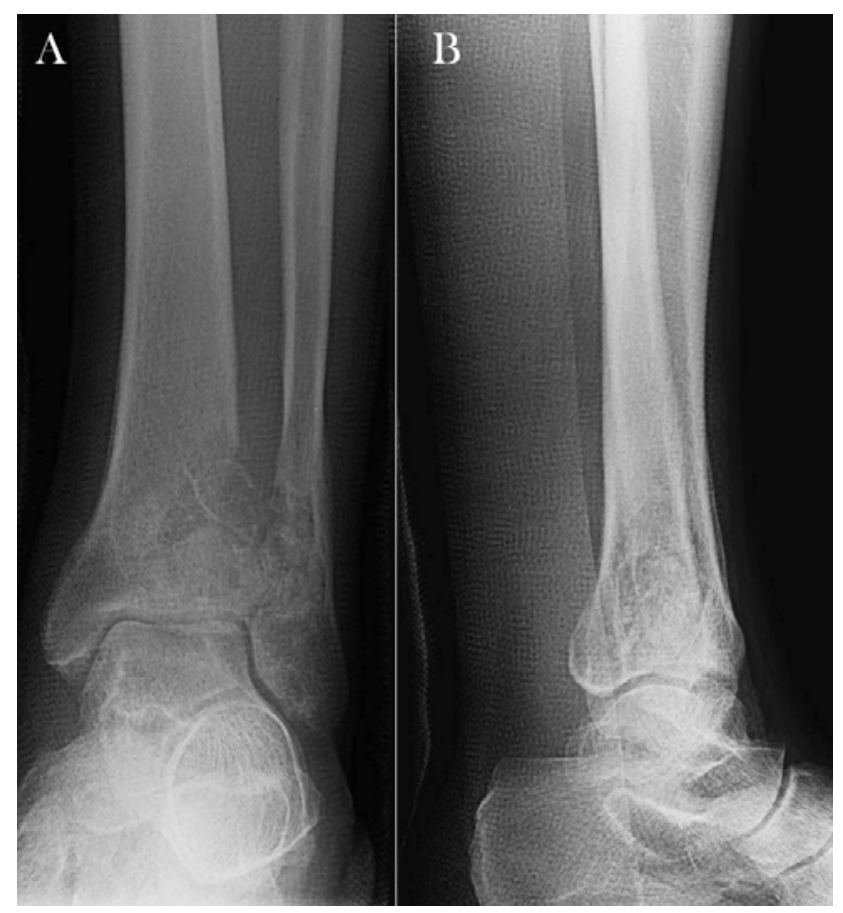

Figure 6AB Post-operative AP and Lateral x-ray showing leg in Plaster of Paris.

Postoperatively the patient was placed in a plaster splint and began mobilization without weight bearing for six weeks.

The pathologist, after consulting the Dutch National Bone Tumours Panel, confirmed the diagnosis of pigmented villonodular synovitis.

Two days after the operation, a CT-scan was made for evaluation of the current status of the operated left ankle joint. There was some air in the transplanted bone and in the soft tissues. No complications were noted. (Fig. 5ABC) Six weeks after surgery the patient visited our outpatient clinic. He noticed slight pain on weight bearing. $\mathrm{X}$-ray showed the leg in a Paris of plaster. (Fig. $6 \mathrm{AB})$

Three and a half years after surgery the patient was free of pain and had virtually no complaints. On physical examination there was no swelling or instability of the ankle. He had a dorsiflexion of $15^{\circ}$ and a plantar flexion of $35^{\circ}$ of the ankle joint. There were no restrictions in daily or occupational activities. 


\section{Discussion}

The etiology of PVS remains unclear. Rao, et al, ${ }^{8}$ suggests a benign tumour arising from synovial fibroblasts and/or histiocytes. Another hypothesis postulates a local disorder of lipid metabolism in the synovial membrane. According to other authors, PVS is an inflammatory reaction to an unidentified etiological agent. 1,5,10 Trauma and hemarthros have also been mentioned as possible causes. ${ }^{3,18}$

Sciot, et al, ${ }^{29}$ studied the karyotypes of 44 specimens of 35 patients with localized $(n=19)$ or diffuse $(\mathrm{n}=16)$ tenosynovial GCT's. They found no difference in the distribution of karyotypic abnormalities between the localized and diffuse form except for trisomies (usually of chromosomes 5 and/or 7), which were more frequent in the diffuse type. They suggested that this variant of the disease is most likely neoplastic in nature.

In literature, the frequency of foot and ankle localisation varies between $11 \%$ and $14 \%$. $^{8,9,10,19}$ More recently Jones ${ }^{20}$ and Rao ${ }^{8}$ calculated a much lower frequency of $3 \%$ and $2.5 \%$, respectively.

In the foot and ankle, two variants have been identified: tenosynovitis and articular synovitis. The articular synovial form most commonly involves the hindfoot and the ankle. Initial tenosynovitis is frequent more distal. ${ }^{7-9}$ In the foot and ankle, the proximity of many tendons around the joints explains the local invasion of either the articular or the tendinous tissues.

Regarding the mode of bone involvement, there are various views. McMaster ${ }^{21}$ theorized that it was through articular cartilage and cortex at chondro-osseus junction that the pigmented villonodular tissue extended into the bone. Chung and Janes ${ }^{6}$ suggested that there is increased joint pressure due to synovial overgrowth which leads to small areas of osteoporosis followed by cystic degeneration of bone. Finally, with fracture of the cyst wall , an exuberant synovial membrane invades the cystic area. On the other hand, Scott ${ }^{22}$ theorized that bone involvement occurs through the growth of villonodular tissue through the vascular foramina. The intra-osseous synovium gets its blood supply conveyed along these vascular stalks.

Roentgenograms in tumoral forms usually demonstrate slightly opaque soft tissues. Although a CT-scan is not necessary for making the diagnosis, it may reveal bone lesions which normal radiographs fail to show. MRI findings are specific and can assist in making the diagnosis. Synovial hypertrophy and deposits of ferromagnetic hemosiderin are typical of PVS. ${ }^{23}$ Low signal intensity is noted in T1 and T2 weighted sequences with enhancement after gadolinium injection and without enhancement after gadolinium in areas of fibrosis. Also, hypointense areas on T1-weighted sequences and hyper-intense areas on T2-weighted sequences correspond to fluid in cystic lesions. ${ }^{13,24,25}$

Various treatments of PVS have been described including radiation therapy, synovectomy, marginal and radical excision. ${ }^{3,4,26}$ In our patient the synovial tissue invaded the articular cartilage and bone. We performed a complete resection of the tumour. Because of a large bone defect after resection, a cancellous bone graft was implanted. Some authors prefer arthrodesis of the weightbearing joint after the synovectomy and/or resection of the tumour. ${ }^{27,28}$ We chose to preserve the ankle joint. 


\section{References}

1. Chassaignac: Cancer de la gaine des tendons. Gazette des Hospitaux Civils et Militaines. 185. 1852.

2. Jaffe $\mathrm{H}$, et al. Pigmented villonodular synovitis, bursitis and tenosynovitis. Arch Pathol. 31:731-765, 1941.

3. Granowitz $\mathrm{S}$ et al. Localized pigmented villonodular synovitis of the knee: report of five cases. J Bone Joint Surg. 49 (1): 122-128, Jan 1967.

4. Flandry F, et al. Current concepts review: pigmented villonodular synovitis. J Bone Joint Surg Am. 69 (6): 942949,1987.

5. Granowitz S, et al. The pathogenesis and long-term end results of Pigmented villonodular Synovitis. Clin Orthop. (114): 335-351, Jan-Feb 1976.

6. Chung $\mathrm{S}$ et al. Diffuse pigmented villonodular synovitis of the hip joint. J Bone Joint Surg. 47: 293-303, Mar 1965.

7. Bonnel $\mathrm{F}$, et al. Tumeur a cellules géantes des gaines synoviales dupied. Med Chir. 6: 72-78, 1990.

8. Rao A, et al. Pigmented villonodular synovitis: a review of 81 cases. J Bone Joint Surg Am. 66 (1): 76-94, Jan 1984.

9. Schajowics F, et al. Pigmented villonodular synovitis of the wrist with penetration into bone. J Bone Joint Surg Br. 50 (2): 312-313, May 1968.

10. Byers $\mathrm{P}$, et al.The diagnosis and treatment of pigmented villonodular synovitis. J Bone

Joint Surg Br. 50B (2): 290-305, May 1968.

11. Groulier P, et al. Pigmented villonodular synovitis of joints: apropos of 16 cases. 58 (4): 259-267, Apr 1991.

12. Leemirijse $\mathrm{T}$, et al. De la tumeur a cellules géantes a la synovite villonodulaire : a propos de quatre cas au niveau du pied. Med Chir Pied. 12: 72-80, 1996.

13. Jelinek $\mathrm{J}$, et al. Imaging of pigmented villonodular synovitis with emphasis on MR imaging. AJR Am J Roentgenol. 152 (2): 337-342, Feb 1989.

14. Konrath $G$, et al. Magnetic resonance imaging in the diagnosis of localized pigmented villonodular synovitis of the ankle: a case report. Foot Ankle Int. 15 (2): 84-87, Feb 1994.

15. Kottal R, et al. Pigmented villonodular synovitis: a report of MR imaging in two cases.

Radiology. 163 (2): 551-553, May 1987.

16. Mandelbaum B, et al.The use of MRI to assist in diagnosis of pigmented illonodular synovitis of the knee joint. Clin Orthop (231): 135-139, Jun 1988.

17. Hirohata K. Light and electron microscopic studies of individual cells in pigmented

villonodular synovitis and bursitis. Kobe J Med Sci. 14 (4): 251-279. Dec 1968.

18. Young J, et al. Experimental production of pigmented villonodular synovitis in dogs. Am J Pathol. 30 (4): 799-811, Jul-Aug 1954.

19. Myers B, et al. Pigmented villonodular synovitis and tenosynovitis: a clinical epidemiologic study of 166 cases and literature review. Medicine. 59 (3): 223-238 May 1980.
20. Jones F, et al.: Fibrous xanthoma of synovium (giant cell tumor or tendon sheath pigmented nodular synovitis): a study of one hundred and eighty cases. J Bone Joint Surg. 51 (1): 76-86, Jan 1969.

21. McMaster P: Pigmented villonodular synovitis with invasion of bone. J Bone Joint Surg. 42 (7): 1170-1183, Oct 1960.

22. Scott P: Bone lesions in pigmented villonodular synovitis. J Bone Joint Surg. 50 (2): 306-311, May 1968.

23. Spritzer C, et al. Magnetic resonance imaging of pigmented villonodular synovitis: a report of two cases. Skeletal Radiol. 16 (4): 316-319, 1987.

24. Dufour $\mathrm{M}$, et al. La synovite villonodulaire hemopigmentee (Hemopigmented villonodular synovitis) J Radiol. 72 (6-7): 363-373, Jun-Jul 1991.

25. Kransdorf $\mathrm{M}$, et al. Soft tissue masses: diagnosis using MRI imaging. AJR. 153 (3): 541-547, Sep 1989.

26. Wu K, et al. Pigmented villonodular synovitis: a clinical analysis of twenty-four cases treated at Henry Ford Hospital. Orthopedics. 3: 751-758, 1980.

27. Rochwerger A, et al. Pigmented synovitis of the foot and ankle: A report of eight cases Foot Ankle Int. 20 (9): 587-590, Sep 1999.

28. Pandey S, et al. Pigmented villonodular synovitis with bone involvement. Arch Orthop Trauma Surg. 98 (3): 217223. 1981.

29. Sciot R, et al. Analysis of 35 cases of localized and diffuse tenosynovial giant cell tumor: a report from the chromosomes and morphology (CHAMP) study group. Mod Pathol. 12 (6): 576-579, Jun 1999.

\section{Acknowledgement}

Special thanks to Dr. F.H.L. Broker and Dr. R. van Nidek for interpretation of the radiological findings. The authors did not receive grants or outside funding in support of their research for or preparation of this manuscript. They did not receive payments or other benefits or a commitment or agreement to provide such benefits from a commercial entity. No commercial entity paid or directed, or agreed to pay or direct, any benefits to any research fund, foundation, educational institution, or other charitable or non-profit organization with which the authors are affiliated or associated. 